\title{
Temporal Activity Patterns of the Spider Wasp Pepsis montezuma Smith (Hymenoptera: Pompilidae) in a Disturbed Lower Montane Rainforest (Manizales, Colombia)
}

\author{
Carlos Restrepo-Giraldo, ${ }^{1}$ Juanita Rodriguez, ${ }^{2}$ and James P. Pitts ${ }^{2}$ \\ ${ }^{1}$ Department of Biology, Universidad de Caldas, Manizales, Caldas, Colombia \\ ${ }^{2}$ Biology Department, Utah State University, Logan, UT 84321, USA \\ Correspondence should be addressed to Juanita Rodriguez, juanitarodrigueza@gmail.com
}

Received 18 October 2012; Revised 6 December 2012; Accepted 6 December 2012

Academic Editor: David G. James

Copyright ( 2012 Carlos Restrepo-Giraldo et al. This is an open access article distributed under the Creative Commons Attribution License, which permits unrestricted use, distribution, and reproduction in any medium, provided the original work is properly cited.

\begin{abstract}
We studied the temporal activity pattern of the spider wasp Pepsis montezuma Smith (Hymenoptera: Pompilidae) in a disturbed lower montane rainforest, which is located in the city of Manizales, Colombia, at an altitude of 2,150 m. Females of this species are diurnal with two peaks of activity: one in the morning and the other in the afternoon. During the morning, nectar foraging occurred at Baccharis latifolia. During the afternoon, females hunted for tarantulas of the genus Pamphobeteus (Araneae: Theraphosidae), which were dragged backwards to the nest by the wasp. The nest was excavated before hunting. This is the first description of the behavior of Pepsis montezuma.
\end{abstract}

\section{Introduction}

Pompilids (spider wasps) are a distinct group of wasps that have an interesting natural history where single spiders are used as hosts. Spider wasps have energetic search behaviors, and distinct morphology, with notably robust bodies and long spiny legs. Short flight durations with rapid movement of their wings and antennae are also distinctive features of this group [1]. Females use spiders as hosts to feed their larvae. They lay a single egg on each subdued spider [2]. After stinging a spider, the female wasp transports the spider to the nest by dragging it backwards, forward, or even flying with it. The nest can be prepared before or after hunting, and a few spider wasps use the spider's nest as their own [3].

Despite their diversity, few pompilid wasp's natural history has been studied, and most of our knowledge is from North America and Europe. Behavioral studies of Pepsis have all been conducted in the USA on Nearctic species [4-8], and natural history is known for less than $9 \%$ of the species in the genus.

In order to add to our knowledge of the biology of spider wasps in South America, specifically of Pepsis species, natural history observations were made in Colombia. A field site in a montane humid forest, near the city of Manizales, Colombia, was found with a high number of active spider wasps. This presented the opportunity to study the activity patterns of this species. Flight length, duration, and frequency were measured, as well as nest entrance and length. Behaviors, and the time of occurrence, were also measured. This work constitutes the first description of the behavior of Pepsis montezuma Smith.

\section{Methods}

2.1. Study Area. The city of Manizales, Colombia, is located in the Central "Cordillera," toward the western slope, at an altitude of $2,120 \mathrm{~m}$. The coordinates for the study area are $5^{\circ} 3^{\prime} 19.9^{\prime \prime} \mathrm{N}-75^{\circ} 28^{\prime} 51.7^{\prime \prime} \mathrm{W}$. The mean temperature is $19^{\circ} \mathrm{C}$ and the relative humidity is $80 \%$. The area is termed a lower montane highly humid forest, according to the system developed by Holdridge [9]. The location chosen has an area of $2,442 \mathrm{~m}^{2}$, is eroded, and has exposed clay soil. It is mainly composed by grass and a tree species-Baccharis latifolia (Ruiz \& Pavón) Persoon-from the family Asteraceae, which is commonly known as "Chilca" in South America. The area is highly disturbed, given its proximity to the city. 
2.2. Observations. The behavioral activity of Pepsis montezuma was observed during three days. Wasps were identified using the keys provided by Vardy [10-12] and a reference collection of Pepsis identified by Vardy at Utah State University. For all three days, exhaustive observations were made from 600 to $1800 \mathrm{hr}$. The nesting, foraging, and hunting behaviors were timed, and flight distance was measured for ten individuals. The depth and entrance diameter of 40 nests were measured.

\section{Results}

Activity of males and females began one and a half to two hours after sunrise (between 800 and $830 \mathrm{hr}$ ). Some wasps emerged from nests, others from mounds of soil surrounded by grass, and others that seemed not to have a burrow rested on the soil. Males and females left the nest or ground and performed short flights for 0.53 to $3.33 \mathrm{~min}(n=10$; $\mathrm{SD}=1.63)$, with a mean length of $9.53 \mathrm{~m}( \pm 4.2 \mathrm{SD})$ on the surrounding vegetation, resting on it for 0.35 to $4.94 \mathrm{~min}$ $(n=10 ; \mathrm{SD}=1.07)$. Males performed shorter flights, $t(8)=$ $3.495, P<0.05$. The mean resting period was longer in males, but there was no statistical difference in resting period between males and females, $t(8)=1.860, P>0.05$. Males and females flew at the same mean speed, $t(8)=0.098$, $P>0.99$ (Figure 1). More short flights by males occurred between 830 and $1030 \mathrm{hr}$. These flights were directed towards the vegetation near the nests of other wasps of the same species. As time passed, the distance covered by flying wasps increased.

After $1030 \mathrm{hr}$, the wasps began foraging for nectar on the flowers of Baccharis latifolia (Asteraceae) while other flight activities decreased. The food plant is usually abundant in areas where soils are moist and blooms continually throughout the year. After about 1130, the wasps sometimes rested inside their nests, engaged in short flights about the area, or occasionally foraged for nectar. After $1500 \mathrm{hr}$, nest locating, nest building, nest cleaning, and hunting were observed. Intruders that approached an occupied nest were attacked and quickly driven away.

The observed nests of Pepsis montezuma were built in the ground previous to hunting. The entrance had a mean diameter of $1.52 \mathrm{~cm}(n=40 ; 0.27 \mathrm{SD})$, which widened to form a chamber where the spider was deposited. The mean tunnel length was $6.74 \mathrm{~cm}(n=40 ; 1.5 \mathrm{SD})$.

Prey capture was observed at a mean distance of $5 \mathrm{~m}$ $(n=5 ; \mathrm{SD}=3.00)$ from the nest entrance. Pepsis montezuma preys on at least one species of the spider genus Pamphobeteus (Araneae: Theraphosidae). A spider was observed bearing a larva on the ventral region of the opisthosoma (Figure 2). Once the spider was stung, the wasp dragged it by walking backwards to a pre-existing cavity previously constructed by the wasp. At approximately $50 \mathrm{~cm}$ from the burrow, the wasp released the spider, hiding it in the vegetation, and returned briefly to fix the nest in the pre-existing cavity before coming back to the spider, which it retrieved. The wasp then dragged the spider into the nest. The observed nesting behavior was abbreviated by Evans [3] as IVPTOC, where the events follow the following, the order: nest construction (I), hunting

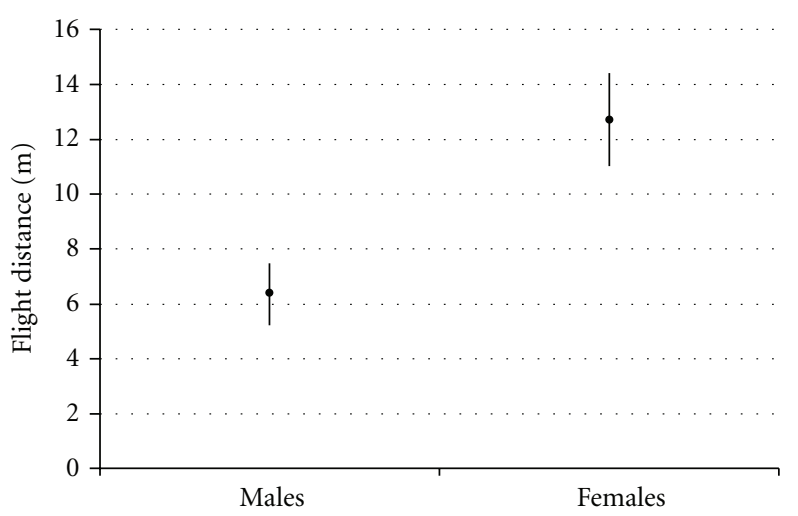

(a)

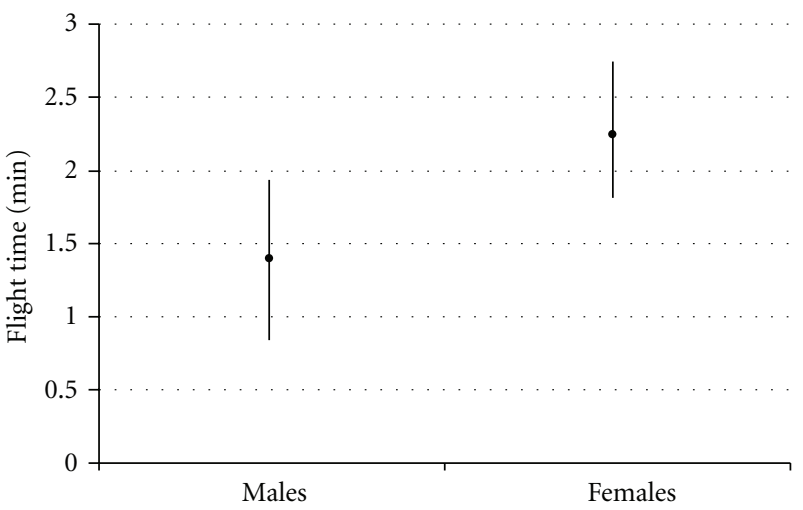

(b)

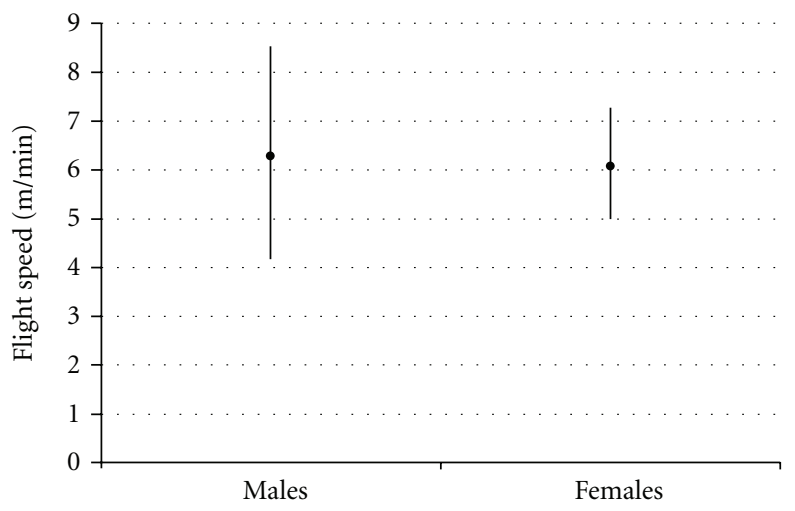

(c)

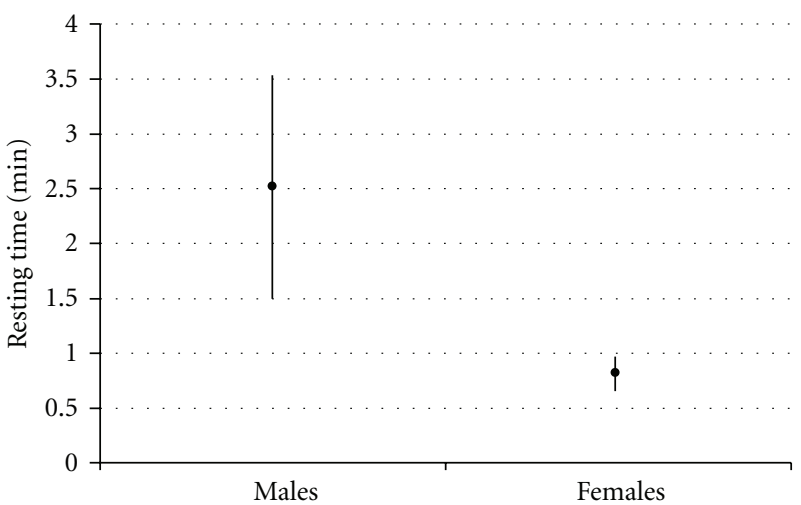

(d)

Figure 1: Mean (a) flight distance, (b) flight time, (c) flight speed, (d) resting time in males and females. 


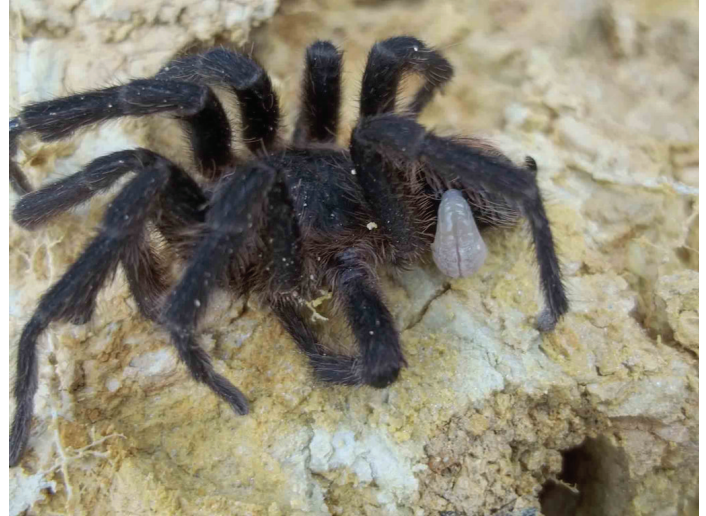

Figure 2: A specimen of Pamphobeteus sp. bearing a larva of Pepsis montezuma on the opisthosoma.

$(\mathrm{V})$, paralysis $(\mathrm{P})$, transportation $(\mathrm{T})$, oviposition $(\mathrm{O})$, and closing (C).

All activity ended by $1730 \mathrm{hr}$. Males aggregated overnight rest on low-lying vegetation. These aggregations disassembled in the morning.

One mating event was observed when two males attempted to copulate with a female on the ground. The smaller male left after about a minute while the larger male copulated with the female for about five minutes.

\section{Discussion}

Pepsis montezuma shows a bimodal activity pattern, with a resting period that occurs when temperatures are the highest. Activity levels show a decrease when it is rainy or cold. This pattern has been documented for Pepsis thisbe Lucas in Texas [13]. Feeding occurs during a few hours in the morning and midday, which are separated by approximately two hours of inactivity. This is the first record for Pompilidae feeding on B. latifolia. Previous studies recorded feeding of Pepsis grossa (Fabricius) a variety of desert plant species, but most of the time was spent on milkweed (Asclepias texana and A. sperryi, Asclepiadaceae), Mexican buckeye (Ungnadia speciosa, Sapindaceae), and honey mesquite (Prosopis glandulosa, Fabaceae), which have short corolla lengths [4] like B. latifolia. Because they feed on few plant species, Punzo [4] suggested a narrow niche for Pepsis. Vardy [10] mentioned a predilection for few plant species, depending on the area. Pepsis montezuma also seems to have a narrow niche, feeding on just one plant species. Nevertheless, the availability of resources could influence their preference for B. latifolia in the area studied.

Hunting behaviors recorded for Pepsis are varied. Most of the species have been observed stinging and dragging the spider backwards to a nesting site, digging the nest, and inserting the spider (VPTIOC) [3]. This behavioral type is the most common in Pompilidae and is thought to be the ancestral condition for the family [3]. There is some behavioral plasticity, however, where the wasp builds the nest before hunting (IVPTOC) [3] -as observed for $P$. formosa [14] and recorded in our observations-or even uses the spider's burrow as a nest (VPOC), as in Pepsis cupripennis [15] and P. mildei [16]. Therefore, three of the eight behavioral types found in Pompilidae are observed in this single genus thus far. The only records for complete hunting behaviors of Pepsis are the ones mentioned herein. More observations are needed to cover the entire behavioral diversity of the group.

The behavior displayed by males, who aggregate on the grass overnight, has been observed in Pepsis [17]. This is a form of "roosting" observed in other aculeate wasp groups. In many species of various groups, males spend the night on different types of plants, but mainly on the stems of shrubs or trees. These aggregations-as recorded herein-usually form in the late afternoon or evening and disassemble in the morning. They can last for weeks, months, or even generations. The aggregations have been suggested to provide protection for predators or have thermoregulatory effects [18].

There are 133 known Pepsis species [10], but behavioral records exist for fewer than ten of them. There is still much more to be done in Pepsis behavioral studies. Most of the records are from North American species occurring in deserts, but this genus is more diverse in the Neotropical region and present in a variety of habitats including grasslands, montane forests, rainforests, and many more [10].

\section{Acknowledgments}

The authors thank Lucas Bartelsman Mejia for taking data for this work in the field, Jaime Florez for his comments on the figures, and Luis Fernando Garcia for identifying the spiders. They also thank the entomological collection at the Biology Department, Universidad de Caldas, Colombia (CEBUC). This work was supported by the National Science Foundation Award DEB-0743763 to JPP and Carol D. von Dohlen and by the Utah Agricultural Experiment Station, Utah State UAES no. 8491 .

\section{References}

[1] F. Fernández, "Avispas cazadoras de arañas (Hymenoptera: Pompilidae) de la region Neotropical," Biota Colombiana, vol. 1, pp. 3-24, 2000.

[2] D. Brothers and J. Carpenter, "Phylogeny of aculeata: chrysidoidea and vespoidea (Hymenoptera)," Journal of Hymenoptera Research, vol. 2, pp. 227-304, 1993.

[3] H. E. Evans, "Comparative ethology and the systematics of spider wasps," Systematic Zoology, vol. 2, pp. 155-172, 1953.

[4] F. Punzo, "Plants whose flowers are utilized by adults of Pepsis grossa Fabricius (Hymenoptera: Pompilidae) as a source of nectar," Journal of Hymenoptera Research, vol. 15, pp. 171-176, 2006.

[5] F. X. Williams, "Life history studies of Pepsis and Hemipepsis wasps in California (Hymenoptera: Pompilidae)," Annals of the Entomological Society of America, vol. 49, pp. 447-466, 1956.

[6] F. Punzo and B. Garman, "Effects of encounter experience on the hunting behavior of the spider wasp, Pepsis formosa (Say) (Hymenoptera: Pompilidae)," The Southwestern Naturalist, vol. 34, pp. 513-518, 1989. 
[7] J. Alcock and M. D. Johnson, "Male behavior in the tarantulahawk wasp Pepsis thisbe Lucas (Hymenoptera: Pompilidae)," Journal of the Kansas Entomological Society, vol. 63, pp. 399404, 1990.

[8] F. Punzo, "Experience affects hunting behavior of the wasp, Pepsis mildei Stål (Hymenoptera: Pompilidae)," Journal of the New York Entomological Society, vol. 113, no. 3-4, pp. 222-229, 2005.

[9] L. R. Holdridge, "Determination of world plant formations from simple climatic data," Science, vol. 105, no. 2727, pp. 367368, 1947.

[10] C. R. Vardy, “The New World tarantula-hawk wasp genus Pepsis Fabricius (Hymenoptera: Pompilidae)—part 1. Introduction and the P. rubra species-group," Zoologische Verhandelingen, vol. 332, pp. 1-86, 2000.

[11] C. R. Vardy, "The New World tarantula-hawk wasp genus Pepsis Fabricius (Hymenoptera: Pompilidae)—part 2. The $P$. grossa-to P. deaurata-groups," Zoologische Verhandelingen, vol. 337, pp. 1-135, 2002.

[12] C. R. Vardy, “The New World tarantula-hawk wasp genus Pepsis Fabricius (Hymenoptera: Pompilidae)—part 3. The $P$. inclyta to P. auriguttata-groups," Zoologische Mededelingen, vol. 79, pp. 1-305, 2005.

[13] F. Punzo, "The biology of the spider wasp, Pepsis thisbe (Hymenoptera: Pompilidae) from Trans Pecos, Texas-II. Temporal patterns of activity and hunting behavior with special reference to the effects of experience," Psyche, vol. 101, pp. 243-256, 1994.

[14] M. A. Cazier and M. A. Mortenson, "Bionomical observations on tarantula-hawks and their prey (Hymenoptera: Pompilidae: Pepsis)," Annals of the Entomological Society of America, vol. 57, pp. 533-541, 1964.

[15] F. G. Costa, F. Pérez-Miles, and A. Mignone, "Pompilid wasp interactions with burrowing tarantulas: Pepsis cupripennis versus Eupalaestrus weijenberghi and Acanthoscurria suina (Araneae, Theraphosidae)," Studies on Neotropical Fauna and Environment, vol. 39, no. 1, pp. 37-43, 2004.

[16] L. Passmore, "California trapdoor spider performs engineering marvels," National Geographic Magazine, vol. 64, pp. 195211, 1933.

[17] F. X. Williams, "Studies in tropical wasps-their hosts and associates," Bulletin of the Hawaiian Sugar Planters' Association Experiment Station, vol. 19, pp. 1-179, 1928.

[18] J. Alcock, "Sleeping aggregations of the bee Idiomelissodes duplocincta (Cockerell) (Hymenoptera: Anthophorini) and their possible function," Journal of the Kansas Entomological Society, vol. 71, no. 1, pp. 74-84, 1998. 

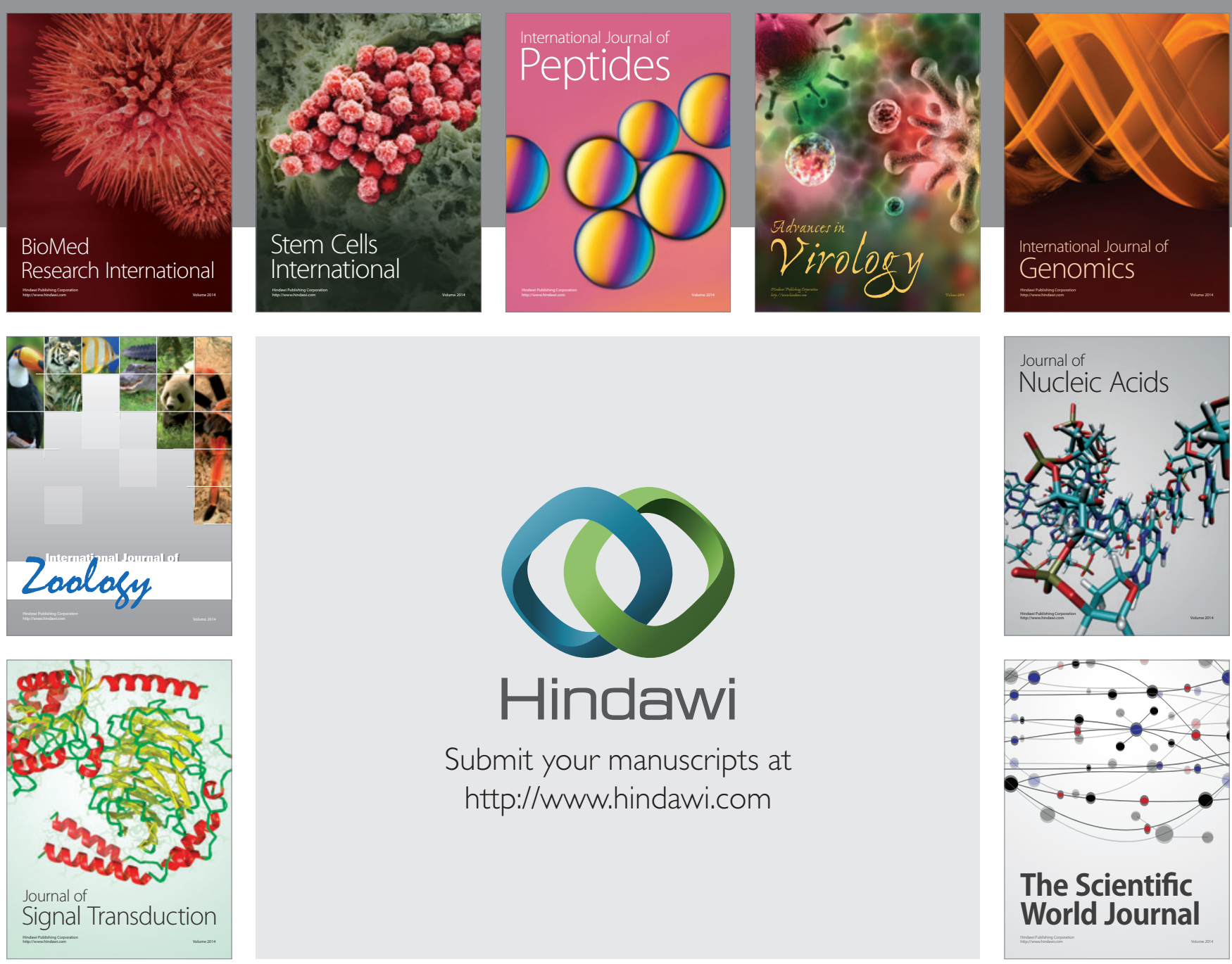

Submit your manuscripts at

http://www.hindawi.com
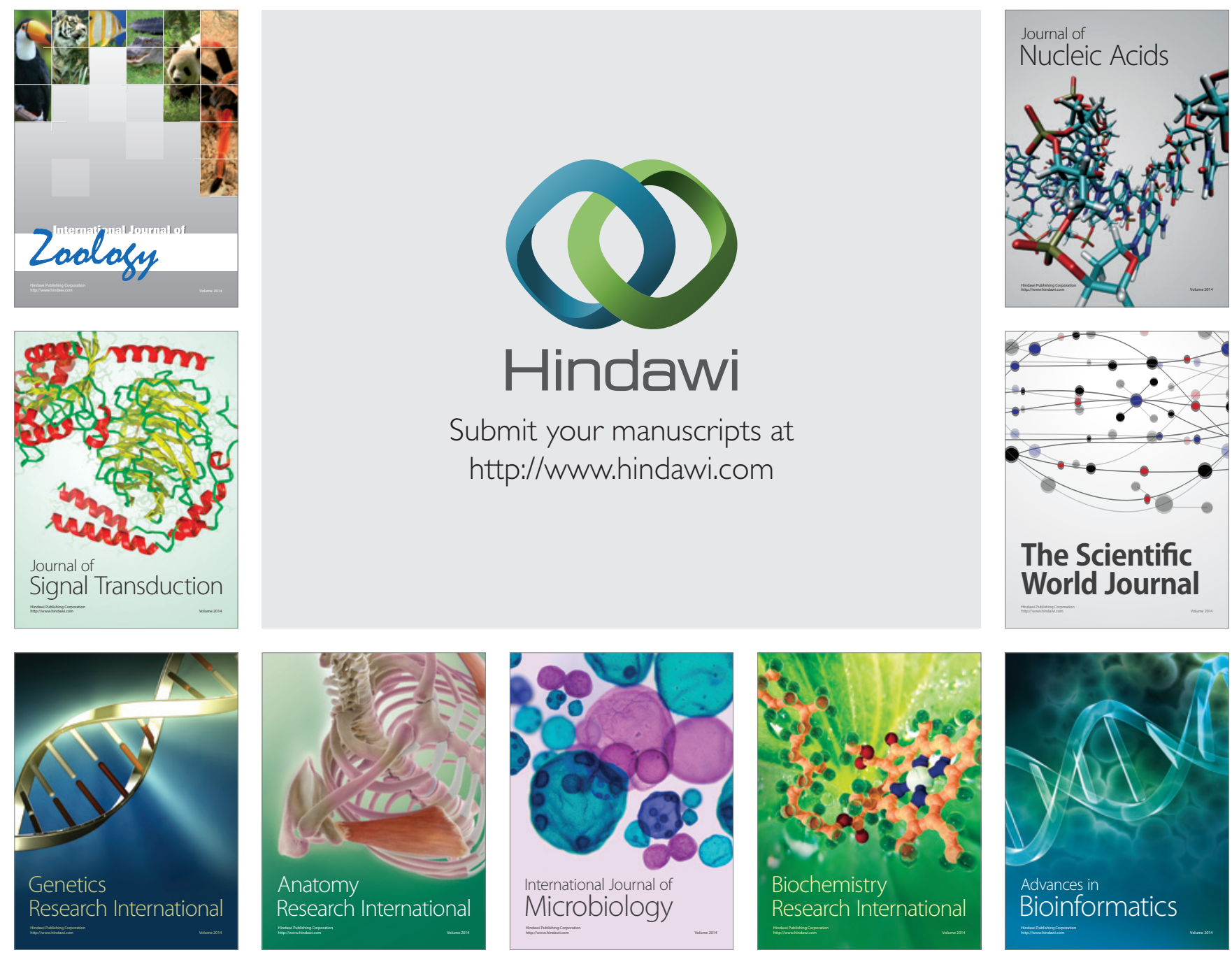

The Scientific World Journal
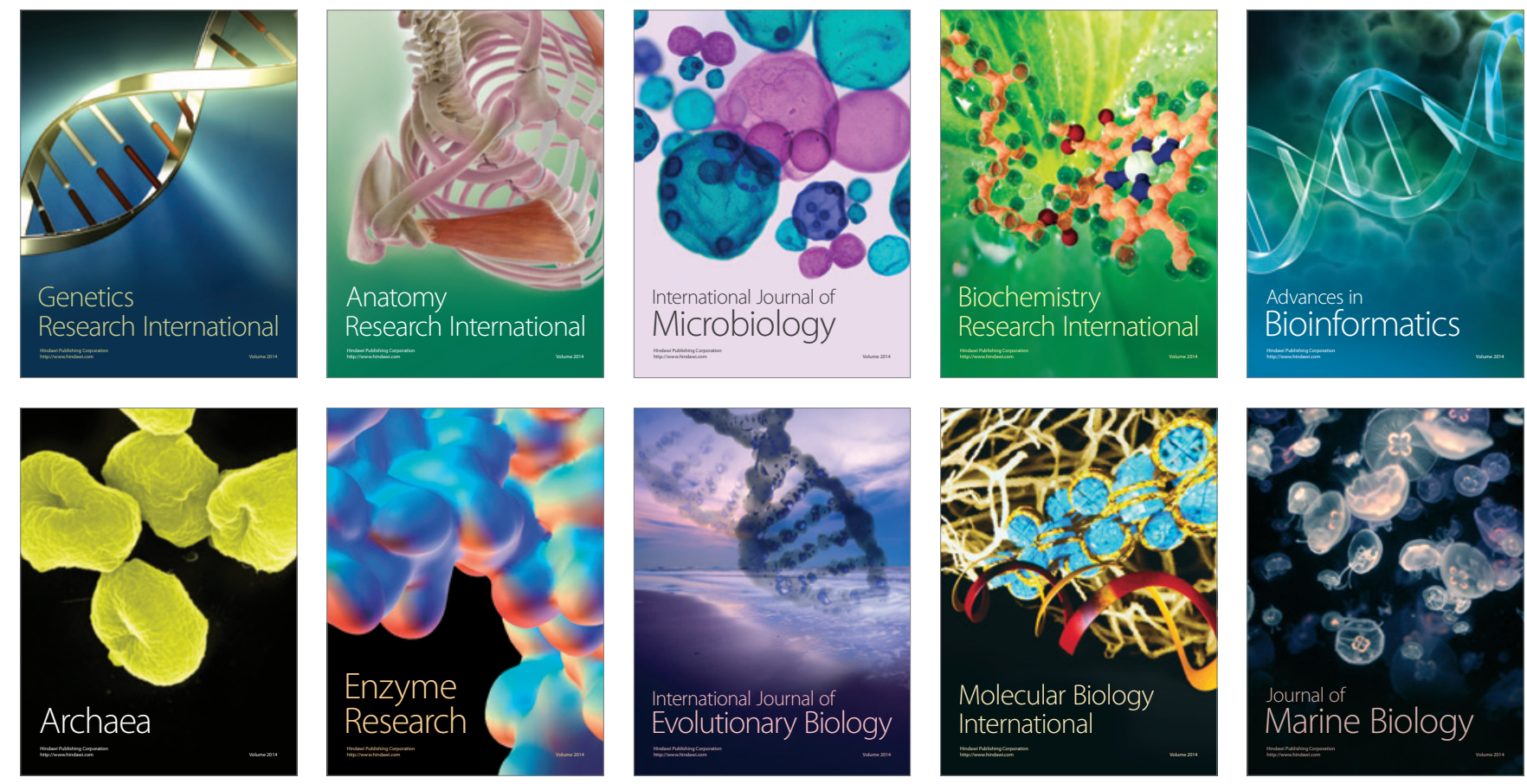